Document downloaded from:

http://hdl.handle.net/10251/173454

This paper must be cited as:

Chávez-Modena, M.; Valero, E.; Miguel González, L.; Broatch, A.; Garcia Tiscar, J.; Felgueroso-Rodríguez, A. (2021). Numerical and experimental analysis of thermoaerodynamic performance in an aero engine surface heat exchanger. Institute of Aeronautics and Astronautics, Inc. 1-12. https://doi.org/10.2514/6.2021-2901

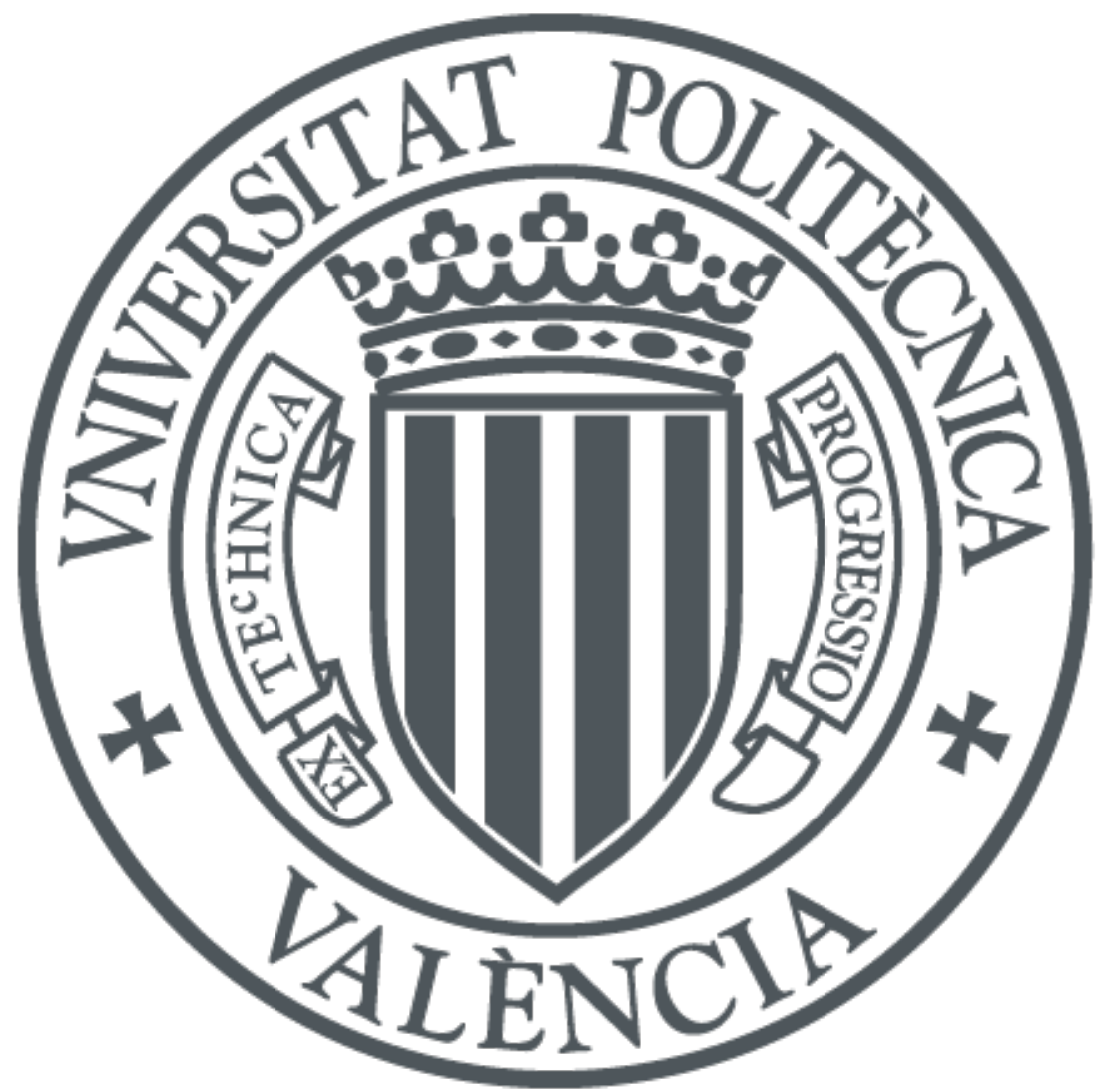

The final publication is available at

https://doi.org/10.2514/6.2021-2901

Copyright Institute of Aeronautics and Astronautics, Inc.

Additional Information 


\title{
Numerical and experimental analysis of thermo-aerodynamic performance in an aero engine surface heat exchanger
}

\author{
Miguel Chávez-Modena*, Eusebio Valero ${ }^{\dagger}$ and Leo Miguel González ${ }^{\ddagger}$ \\ Universidad Politécnica de Madrid (UPM), 28040 Madrid, Spain \\ Alberto Broatch ${ }^{\S}$, Jorge García-Tíscar ${ }^{\mathbb{I l}}$, and Andrés Felgueroso" \\ Universitat Politècnica de València (UPV), 46022 Valencia, Spain
}

\begin{abstract}
A surface air-cooled oil cooler (SACOC) is a passive heat exchanger used to evacuate a large quantity of heat from the oil circuit of a turbofan engine to its secondary flow with minimal perturbation. Using the secondary flow as a heat sink has the advantage of the evacuated enthalpy being available in the nozzle. The performance of a SACOC is therefore measured in terms of maximum heat release capacity with minimal pressure loss and flow perturbations.

These heat exchangers are typically composed of parallel fins and are usually tested in bespoke wind tunnels where the interaction between the three-dimensional high velocity flow and the heat exchangers is evaluated. Modern numerical computations that include the solution of the fluid equations in the flow field and a conjugate thermal problem can be also performed. This numerical approach, once validated, allows a complete and computationally affordable analysis of the aero-thermodynamic performance of the SACOC. In this work, a first comparison between both experimental and computational perspectives is presented in terms of pressure and temperature profiles to achieve a complete characterization of the device. This double experimental numerical perspective allows comparing the behaviour of the different fins of the SACOC depending on their relative position but also to trust the numerical conclusions with experimental robust data.
\end{abstract}

\section{Nomenclature}

$\begin{array}{ll}x, y, z & =\text { spatial coordinates } \\ \mathbf{u} & =\text { fluid velocity field } \\ u_{\text {exp }} & =\text { experimental inflow profile } \\ T & =\text { temperature field } \\ T_{\infty} & =\text { inflow temperature } \\ \mathbf{n} & =\text { wall normal direction } \\ U_{\infty} & =\text { maximum inflow velocity } \\ b, h, s, t, L, H, W & =\text { geometrical dimensions } \\ \rho & =\text { fluid density } \\ \dot{Q} & =\text { heat transfer } \\ R e & =\text { Reynolds number } \\ M & =\text { Mach number } \\ T_{c} & =\text { temperature at the bottom of the fins }\end{array}$

\footnotetext{
*Assistant Professor, Dept. of Applied Mathemathics, UPM; Center for Computational Simulation, UPM, m.chavez@upm.es.

${ }^{\dagger}$ Full Professor, Dept. of Applied Mathemathics, UPM; Center for Computational Simulation, UPM, eusebio.valero@upm.es.

$\doteqdot$ Associate Professor, Dept. of Fluid Mechanics and Propulsion, UPM; Center for Computational Simulation, UPM leo.gonzalez@upm.es.

${ }^{\S}$ Full Professor, CMT-Motores Térmicos, UPV, abroatch@mot.upv.es

II Assistant Professor, CMT-Motores Térmicos, UPV, jorgarti@ mot.upv.es

" Graduate Research Assistant, CMT-Motores Térmicos, UPV, anfelrod@mot.upv.es
} 


\section{Introduction}

A DVANCED oil cooling strategies for more efficient engine architectures are one of the technological challenges that demand more intense research. New engine designs based on inlet air stream and the fuel circuit are approaching their limits as typical cold sources. Complex coupled problems are found in this kind of mechanical systems, where the thermal part must be treated adequately. It should be taken into account that the heat removal by the aircraft structure will be limited using composite materials with lower operational temperature and thermal conductivity properties. Furthermore, the limitation on the maximum fuel temperature decreases the viability of the fuel tank as a cold source. Therefore, a novel engine cooling strategy seems to be a new industrial demand. In this context, the evaluation of the thermal performance of an Air Cooled Oil Cooler (ACOC) heat exchanger assembled on the inner wall of the secondary duct of a turbofan, could be an interesting quantitative study. The goal of such designs is to use the available surface as a heat exchanger between the air and the oil. To increase the thermal performance, the wet area is increased by adding longitudinal fins, reaching the required heat dissipation power. Such a design implies a strong compromise between the aerodynamic penalties, quantified by the drag increase or pressure drop, and the improvement in the thermal performance of the heat exchanger. The developed research presents an innovative aero-thermal study by testing the new heat exchanger concept in a 3D shaped transonic wind tunnel capable of reproducing the flow condition within the bypass of an engine.

This surface air/oil heat exchanger (SACOC) can be located on the lip separating the engine bypass flow from the core flow, between the fan and the downstream outlet guide vane, but other locations can be proposed. The SACOC is used to evacuate, in the bypass air stream, a large quantity of heat contained in the oil (contributing therefore to the thrust of the engine) with minimal perturbation and therefore a minimal impact on Specific Fuel Consumption (SFC). The coolant source is the bypass mass flow delivered by the fan. In addition, this device can also contribute to the de-icing of the separation lip between the core flow and the bypass flow, making therefore an efficient use of the extracted heat. The SACOC is finally installed in a location presenting high levels and concentrations of mechanical stresses. The superposition of the structural function of this SACOC, its de-icing ability, and its cooling function is a completely new combination. Obviously, the performance of the SACOC is measured in terms of maximum heat release capacity with minimal perturbation of the flow, in terms of pressure loss and acoustic emission.

Surface Air Cooled Oil Coolers are normally composed of parallel fins integrated in the inner wall of the secondary duct of a turbofan. The geometrical characteristics and location of the fins within the engine are designed to minimize aerodynamic effects (drag and noise increments) while maximizing thermal exchange. This heat exchanger configuration introduces less aerodynamic perturbations than current plate/tubes heat exchanger modules. From an aerodynamic point of view, the measured averaged total pressure losses increased approximately $1 \%$ relative to the clean configuration (without the presence of the fin array). These losses were estimated for the full annular section of a turbofan with a bypass ratio equal to 6 [1]. The analysis of the interaction between the three-dimensional high velocity bypass flow and the heat exchangers is essential to evaluate and optimize the aero-thermodynamic performance, and to provide data for engine modeling.

Computational fluid dynamics (CFD) approaches have been extensively applied to the study of flow and heat transfer

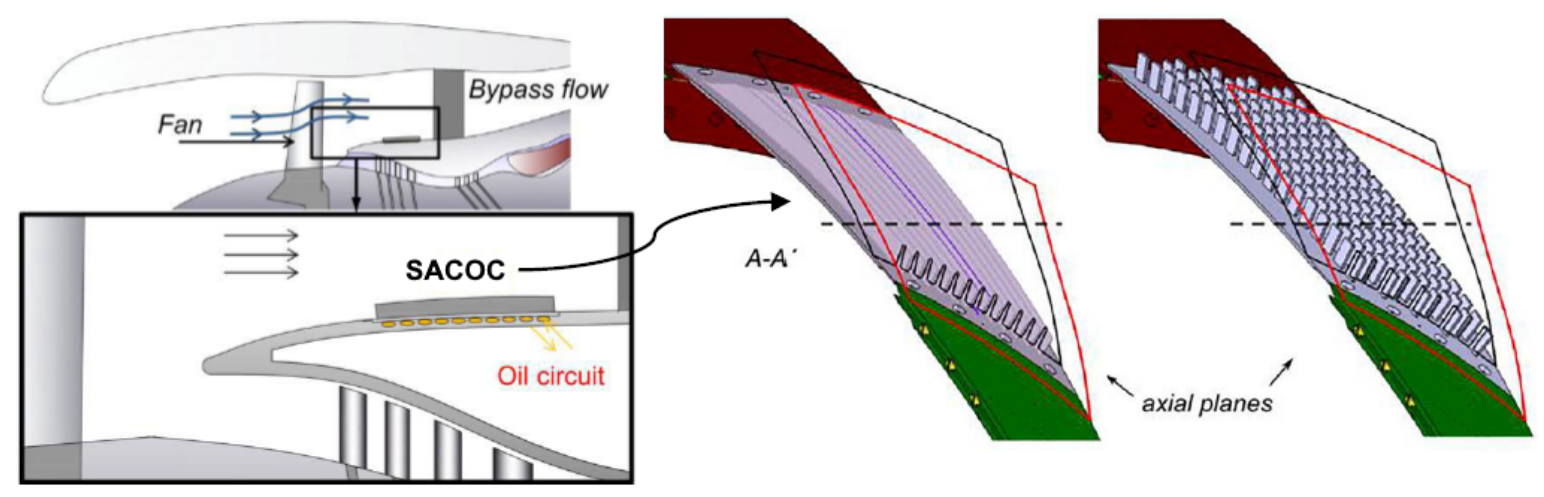

Fig. 1 Configuration studied by UPV, VKI and Purdue University [1, 2]. 
in heat sinks, as can be seen from the works by Jonsson and Moshfegh [3] and Biber and Belady [4]. Outirba and Hendrick [5] conducted an experimental study on surface-air-cooled oil coolers (SACOCs), describing a new test rig that allowed complete tests of SACOC breadboards. Ko et al. [6] studied the effect of SACOC installation using numerical methods. In this paper, an efficient numerical procedure for the study of cooler installation involving bypass ducts was proposed and successfully demonstrated, and important design variables were clearly identified. Kim et al. [7] performed a detailed experimental study from which the results validated this numerical work. To assess the performance of a heat exchanger, an appropriate performance metric should be used. Adams [8] and Doo et al. [9] used those factors to examine the aero-thermal performance of variously shaped, primary surface heat exchangers. Although the loss of energy inside a heat exchanger usually arises near solid-wall regions such as the fins, losses due to complex flow mixing inside the flow passage are also important. Doo et al. [10] assessed the pressure loss mechanism inside a cross-corrugated plate-type heat exchanger using the volumetric entropy generation rate. This arrangement results in a strong mixing layer between the plates. Although there have been various fundamental studies on pin-fin shaped surfaces for heat exchangers, usually those are done under the condition of idealized heat transfer, without considering the bypass effect, which makes the problem complex [11,12]. It is necessary to carry out studies on the high-speed bypass effect, in relation to the fin shapes of various heat exchangers, to understand the advantages of enhanced heat transfer characteristics for application to aero engines.

Recent experiments in a particular the air/oil heat exchanger design (as shown in Fig. 11) composed by fins aligned to the flow direction and integrated in the surface of the core/bypass flow splitter, downstream of the flow bifurcation, have been performed by UPV in collaboration with the von Karman Institute (VKI) and Purdue University [1, 2].

In this work, a numerical methodology, able to solve the coupled problem and to evaluate the thermal and aerodynamic performance of the SACOC is presented, together with a detailed comparison between the numerical and experimental results aiming to prove the validity of this approach as a useful design tool.

\section{Methodology}

\section{A. Description of the problem.}

We propose to simplify the intrinsic complexity that is found in the technological problem described in the previous section. The first step is to use a simplified geometrical model to examine the aerothermal performance of a finned surface in a reduced part of the global geometry, see Fig. 2. In this simplified geometry, the slight curvature of the model normally present in industrial designs will be neglected in the computational domain. The geometric dimensions are normalized to the wind tunnel height, $H$. The wind tunnel dimensions are width, $W / H=1$, and length, $L / H=5.35$. Fins are characterized with a length, $L F I N / H=1.25$, height, $H F I N / H=0.2$, with the leading and trailing edge at 45 degrees, thickness, $W F I N / H=10^{-2}$, and a separation between fins, $S F I N / H=2.175 \cdot 10^{-2}$.

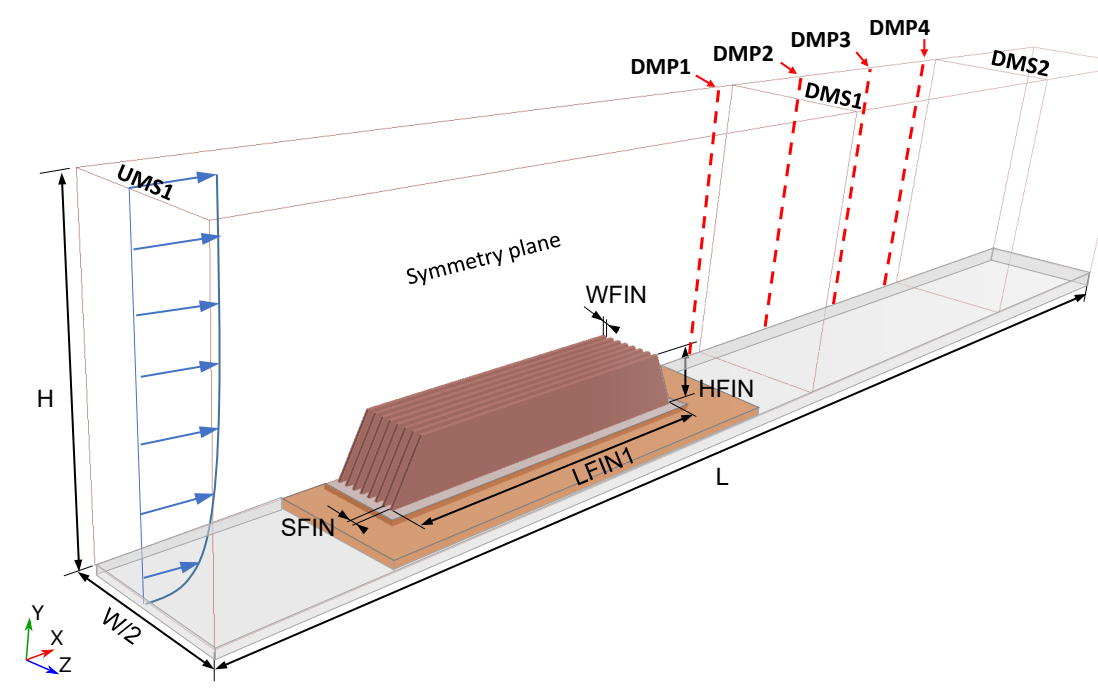

Fig. 2 Geometry used for the symmetric case with 8 fins and location of the measurement profiles. 
The geometry used to examine the heat exchange performance contains 16 fins The fins lie on a base with a length $L B / H=1.33$, height $H B / H=1.5 \cdot 10^{-2}$ and width $W B / H=0.58$. The base is surrounded with thermoplastic material, a distance, $D U / H=0.16$ and a thickness, $W U / H=5 \cdot 10^{-2}$. Finally, the bottom wall is a thick steel plate with a thickness $W S / H=5 \cdot 10^{-2}$. A symmetry condition is used for the mid plane $Z=0$ and only half domain, 8 fins, is finally computed, see Fig. 2 The fins leading edge is at $X / H=0.75$. Additionally, the locations of the measurement of the velocity profiles are shown in Fig. 2. UMS1 $(X / H=0)$, DMS1 $(X / H=2.5)$ and DMS2 $(X / H=4)$, which stand for Upstream Measurement Section 1 and Downstream Measurement Section 1 and 2, respectively, while the Downstream Measurement Profiles are defined as DMP1 $(X / H=2.4)$, DMP2 $(X / H=2.8)$, DMP3 $(X / H=3.2)$ and DMP4 $(X / H=3.6)$.

\section{B. Experimental Setup}

The High Mass-flow and High Temperature (HMHT) flow bench, installed in the 8P laboratory of UPV, is a multipurpose experimental facility for aerodynamic studies in both automotive [13-15] and aeronautical engineering [16], as it provides a fairly large flow rate, more than $2 \mathrm{~kg} / \mathrm{s}$ cold flow and hot flows at temperatures that can reach $1000^{\circ} \mathrm{C}$ with $1 \mathrm{~kg} / \mathrm{s}$ flow rates. This facility is powered by a $500 \mathrm{~kW}$ two-stage centrifugal compressor in series with a 1 MW Diesel combustor. This setup allows performing tests in which both the Mach and Reynolds numbers of the flow can be controlled.

In this facility, a continuous mass flow rate of $2.15 \mathrm{~kg} / \mathrm{s}$ at $3 \mathrm{bar}(\mathrm{A})$ and $30^{\circ} \mathrm{C}$ is available at the measurement room. To regulate the total mass flow delivered to the test room, a series of venting valves are placed in the main pipe between two settling tanks. These reservoirs of $3 \mathrm{~m}^{3}$ are capable of dampening sudden changes in the operating conditions, which helps to protect different parts of the facility and deliver a more uniform and controlled mass flow to the test room. A schematic of the facility is shown in Fig. 3

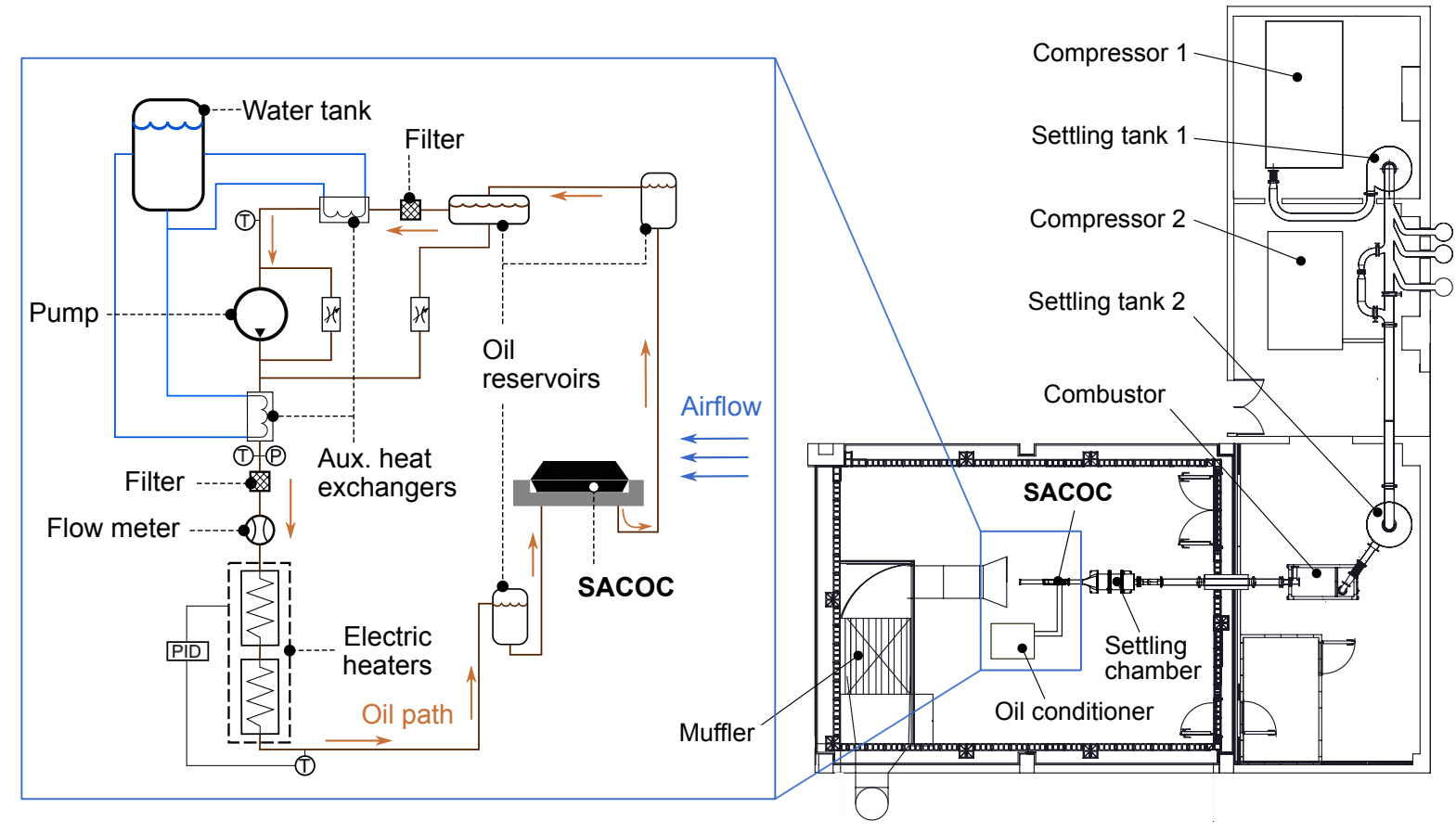

Fig. 3 Detail of the oil conditioning system (left) and schematic of the facility and wind tunnel (right).

\section{Wind tunnel}

In the test room of the HMHT stand, a bespoke modular rig is installed. It is principally formed by a settling chamber, a transition device, a distortion panel holder, and the test section where SACOC is fixed. The wind tunnel, depicted in Fig. 4. discharges with a large silencer that is then routed upward outside of the building to avoid noise pollution. 
The flow is delivered from the HMHT stand through an S-shaped pipe. At the top of this pipe, a tap was set to characterize the incoming air temperature. This pipe drives the flow into the settling chamber via a pierced ending designed with such flow properties that enhances a smooth transition to the test chamber. The settling chamber is a reservoir contemplated to stagnate the fluid, diminish the turbulence level of the flow, and to straighten the streamlines upstream the test section. Several CFD studies were performed to determine the best configuration of the settling chamber and the best performance was found with a configuration based on Purdue's PETAL settling chamber [17]. In order to achieve better flow conditions in the test section, two honeycomb straighteners are placed inside the settling chamber.

Afterwards, to gently drive the flow into the test section, a 3D-printed transition which connects the circular settling chamber with a squared-pipe is placed. The interior surface of the transition has been treated to be as smooth as possible and the geometry presents no abrupt changes to avoid flow detachment. Then, the flow develops in the straight section and reaches a distortion screen capable of transforming a uniform flow profile into the required pressure profile, that must mimic the profile measured in the real engine. Basically, the distortion screen is a 3D-printed honeycomb panel with variable porosity which induces a determined pressure drop depending on that porosity (detail of Fig. (4). Pores have a hexagonal shape as it is structurally sound and produces less pressure drop across the panel. As the test section represents only a close region around the actual exchanger, the profile is then reproduced with high accuracy until close to the top wall of the tunnel, since the real engine is larger and for the experiments a boundary layer will be necessarily generated by the upper wall. Between the distortion screen and the test section, a straight pipe is placed, so the first measurement plane, UMS1, is $2.3 H$ downstream panel.

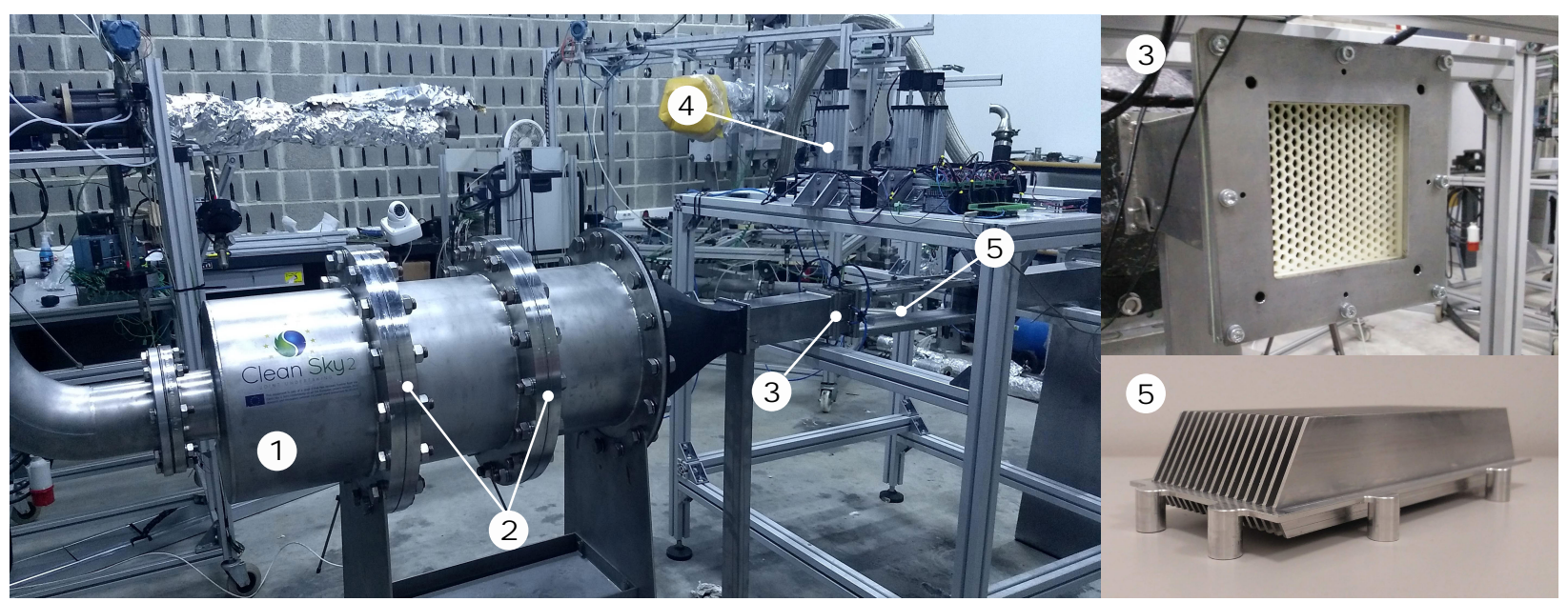

Fig. 4 Experimental test rig with distortion screen and SACOC details. (1) Settling chamber; (2) Honeycombs; (3) Distortion screen; (4) Traverse system; (5) SACOC.

The test section is a square duct with the lateral and top walls made of borosilicate, specially treated for laser wavelength transparency. There are three apertures on the top wall of the test section to allow intrusive measurements. In case non intrusive techniques are required, the top wall can be replaced by a continuous borosilicate glass. To allow thermal measurements with infrared cameras, additional walls with specially treated windows in the SACOC region for infrared transparency in the spectrum from 0.3 to $13 \mu \mathrm{m}$ can be installed. These walls are made of aluminium and present a hole where a window attachment can be placed. This attachment is a rectangular 3D printed part with the window off-center to allow a wider field of view when rotating the attachment.

The Surface Air-Cooler Oil-Cooled, SACOC, in the experiments is a heat exchanger made of aluminium AW7075 T651 [18]. On the oil side, 18 fins with a height 30\% HFIN and also the same angle at both leading and trailing edges with the same thickness are symmetrically distributed. To enhance the heat transfer, the oil circuit is in counterflow, i.e. the oil flows beneath the SACOC in the opposite direction to the air above. Since the bottom wall where the SACOC is mounted is made of steel, and to maintain the heat exchanger as adiabatic as possible (extracting heat through the SACOC solely), a 3D printed oil pan is attached to the wall whereas the exchanger is attached to the oil pan. The material utilized for the oil pan is ULTEM 1010 [19], a thermoplastic ideal for long-term heat resistance. The extra aluminium surface compared to the numerical case needed to attach the exchanger to the oil pan can be considered negligible.

Finally, a straight section discharges the flow to the ambient. This pipe is facing the ventilation system so the air 
leaves the test room smoothly.

\section{Oil conditioner}

Oil that responds to SAE $5 \mathrm{w}-30$ rheological and thermal specifications [20, 21] is used, although almost any type of lubricant can be used in this circuit. The oil is driven throughout the circuit by means of a pump. Upstream the pump, a water-cooled heat exchanger reduces the temperature below $110^{\circ} \mathrm{C}$, with a typical drop of $40^{\circ} \mathrm{C}$. The pump works at a constant speed of $1450 \mathrm{rpm}$ with a power of $370 \mathrm{~W}$, so to regulate the mass flow in the circuit a bypass with a manually controlled valve is used. Then, the oil passes through another heat exchanger devoted to keep the flow meter temperature at the nominal value of operation, with a temperature typically under $60^{\circ} \mathrm{C}$. In between the heat exchanger and the flow meter, the filter eliminates possible impurities that could be created along the circuit, using a series of paper walls with micrometric porosity. Once filtered, the fluid passes through a high precision Coriolis mass flow meter.

Afterwards, the oil temperature is increased by means of an electric heater. This element is composed of two electrical resistors mounted in series, with 2.6 and $2.5 \mathrm{~kW}$ respectively. A thermocouple is set after the electric heater to feed a PID control system that regulates the power needed in the resistors to reach the desired fluid temperature. Finally, the oil goes to the SACOC oil pan. To ensure the pan is filled up with oil and no air bubbles are retained below the aluminium, two oil reservoirs are placed before and after the exchanger, at higher altitude.

Once the lubricant leaves the SACOC and the outlet reservoir, it returns to the oil storage tank. The pump suctions oil from this tank, passing it through a filter that avoids the entrance of dirtiness into the circuit. Additionally, one branch connects the tank to the main circuit downstream the pump, so if the pressure exceeds a certain value, the valve opens and returns fluid to the tank. A scheme showing the oil conditioner operation is displayed in Fig. 3 .

\section{Measurements}

For the aerodynamic measurements, a set of Kiel probes of $3.2 \mathrm{~mm}$ diameter has been utilised. Kiel probes have a surrounding shield around the pressure port, so they are not influenced by swirling, being also less sensitive to the flow direction. In this way, Kiel probes are the best option to determine the total pressure in the section. To perform the measurements in an automatized way, traverse systems have been designed and constructed. In total, 3 biaxial traverses, one for each measurement plane, are used. Each system is composed by two stepper motors - one per each axiscontrolled by an Arduino via MATLAB. GE UNIK 5000 sensors with a range up to 6 bar and an accuracy of $0.2 \%$ F.S. are used to determine the pressure values. The acquisition process is carried out by a NI PXI system, also operated through MATLAB.

For thermal measurements, the Kiel probes have also incorporated T-type thermocouples, so both total pressure and temperature can be acquired at the same time. However, due to a gap between the location of the thermocouple and the top of the head, the bottom-most region cannot be reached by this thermocouple. To perform a more precise analysis of the temperature variation, $4 \mathrm{~K}$-type thermocouples are centered downstream the SACOC fins on the lower wall to see the evolution of the thermal boundary layer at DMP1, DMP2, DMP3 and DMP4. These thermocouples can be moved to analyze the temperature distribution along their verticals.

To measure the heat exchanged during the process, both inlet and outlet oil temperatures of the oil pan are measured at different radius and at the centre of the pipe: three RTDs are used to characterize the radial temperature distribution and one is inserted co-axially to the pipe line. Averaging the temperature measurements at each section and computing the difference, the heat dissipated by the SACOC can be calculated taking into account the mass flow rate of oil circulating across the pan, assuming a constant heat capacity:

$$
\dot{Q}=\dot{m} \Delta h=\dot{m} c_{p} \Delta T=\frac{\dot{m} c_{p}}{4}\left(\sum_{i=1}^{4} T_{\mathrm{in}_{i}}-\sum_{i=1}^{4} T_{\mathrm{out}_{i}}\right)
$$

A FLIR A400 thermographic camera is used for measuring the wall temperature distribution of the specimen, from which the heat transfer efficiency of the prototype can be estimated. To validate the results obtained with the IR camera, surface K-type thermocouples can be introduced through the bottom screws to measure the aluminium temperature at different points. For a better determination of the temperature distribution, the SACOC and its surroundings are painted in black with an special graphite-based paint with high conductivity, which does not modify the temperature on the surface. The result obtained with the thermographic camera is displayed in Fig. 5 The evolution of the temperatures shown in the right side of the figure evidences a considerable increase between the leading and the trailing edge. It is also interesting to observe the effect of the insulation material on the sudden decrease in temperature after the fins. However, although temperatures follow a similar trend along the SACOC span, they decrease as they approach the lateral borders. 

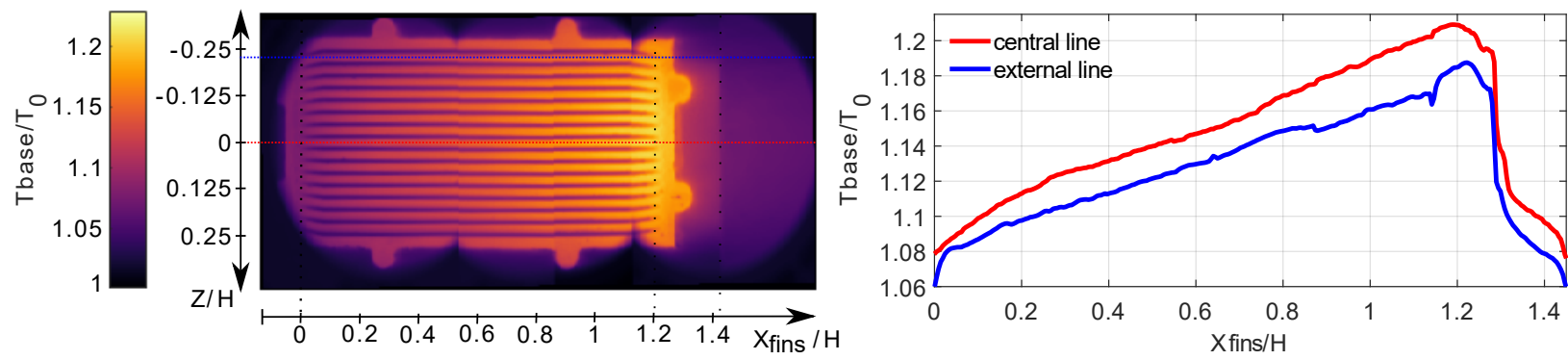

Fig. 5 Image composition from the IR camera (left) and temperature evolution in the center line $(Z / H=0)$ and the external line $(Z / H=0.235)$ (right)

\section{Numerical}

\section{Governing equations and boundary conditions (fluid and solid)}

Let us consider the steady turbulent compressible fluid that flows through a duct that contains a finned surface where a three-dimensional conjugate heat transfer problem is also coupled. A schematic description of the model problem is given in Fig. 22 The problem domain can be decomposed in two parts: the fluid part where the compressible Reynolds-averaged Navier-Stokes (RANS) equations are solved and a solid part where a heat transfer problem is also solved. Both problems are coupled by heat transfer through the flat plate surface, where no-slip velocity and heat conduction conditions are applied. Below, the subindexes $f$ and $s$ are used to determine the fluid and solid temperature regions, respectively. Notice that the solid is divided into three different materials to reproduce the experiment. Aluminium for the SACOC model, ULTEM 1010 [19] where the SACOC model lies and steel for the wind tunnel floor.

Considering the air as an ideal gas, the continuity, momentum, and energy nondimensional equations for the steady, compressible, and turbulent flow are:

$$
\begin{aligned}
\frac{\partial \rho u_{i}}{\partial x_{i}} & =0, \\
\frac{\partial \rho u_{i} u_{j}}{\partial x_{j}} & =\frac{\partial p}{\partial x_{i}}+\frac{\partial}{\partial x_{j}}\left[\frac{1}{\operatorname{Re}}\left(\frac{\partial u_{i}}{\partial x_{j}}+\frac{\partial u_{j}}{\partial x_{i}}\right)-\rho \overline{u_{i}^{\prime} u_{j}^{\prime}}\right], \\
\frac{\partial \rho u_{i} T_{f}}{\partial x_{i}} & =-\frac{\partial}{\partial x_{i}}\left(-\frac{1}{\operatorname{RePr}} \frac{\partial T_{f}}{\partial x_{i}}+\rho \overline{u_{i}^{\prime} T_{f}}\right),
\end{aligned}
$$

where the equation of state for perfect gases is also added to the system (2)-(4). The distances will be nondimensionalized with the wind tunnel height $\mathrm{H}$, velocity with the maximum inflow value $U_{\infty}$, pressure with the outflow static pressure $P_{s}$, temperatures and density with the inflow values $T_{\infty}$ and $\rho_{\infty}$ respectively. Consequently, the nondimensional fluid variables in the equations are listed as: $\rho$ is the density, $u_{i}$ is the velocity in the $i$ direction, $p$ is the pressure, $u_{i}^{\prime}$ is the turbulent deviation of the velocity, $T_{f}$ is the temperature.

The dominant nondimensional numbers are: the Reynolds number defined as $R e=\rho_{\infty} U_{\infty} \mathrm{LFIN} / \mu$, the Prandtl number $\operatorname{Pr}=C_{p} \mu / k_{f}$. Where $\mu$ the fluid viscosity, $k_{f}=k_{\text {air }}$ the fluid (air) thermal conductivity and $C_{p}$ specific heat. Three of them are computed through the Sutherland's law. Regarding the solid properties, Table 1 shows the aluminium, ULTEM 1010 and steel properties.

\begin{tabular}{l|ccc} 
& Al AW7075 T651 [18] & ULTEM 1010 [19] & Steel AISI 304 [22] \\
\hline Density, $\rho\left[\mathrm{kg} / \mathrm{m}^{3}\right]$ & 2810 & 1270 & $8055-7930$ \\
Specific heat, $C_{p}[\mathrm{~J} / \mathrm{kg} \cdot \mathrm{K}]$ & 960 & 2000 & $480-500$ \\
Thermal conductivity, $k_{s}[\mathrm{~W} / \mathrm{m} \cdot \mathrm{K}]$ & 130 & 0.21 & $15.1-16.2$
\end{tabular}

Table 1 Properties of the materials used in the numerical setup.

Equations (2)-(4) are complemented with the boundary conditions shown in Fig. 6 . As the problem presents a symmetry plane $Z=0$, a symmetry boundary is included in the simulation, see Fig. 6 For the inflow boundary 
conditions, an experimentally measured inflow total pressure and temperature profile, the turbulence intensity and viscosity ratio values are imposed. For the outflow, pressure, $p=p_{s}$, outlet boundary condition is used and the temperature is fixed to the inlet value, $T_{f}=T_{\infty}$.

The top and the other lateral walls adiabatic no slip boundary conditions are considered $\partial T / \partial n=0$ where $n$ is the wall normal direction. For the bottom wall and the fins, no slip boundary condition is used for the velocity and heat transfer is allowed between the three solids and the air.

The equation that models the heat conduction effects of the conjugate heat transfer problem in the solid region inside the fins and floor is:

$$
\nabla^{2} T_{S}=0
$$

where $T_{S}$ is the solid temperature. The boundary conditions $\frac{\partial T_{s}}{\partial n}=0$ and $T_{s}=T_{\text {dist }}$ are used for the fins surface and the fins horizontal base respectively, where $T_{\text {dist }}$ is the experimental temperature distribution shown in Fig. 5 . Additionally, the coupling between both the compressible fluid problem and the heat transfer problem is given by the CHT boundary conditions:

$$
\begin{aligned}
T_{s} & =T_{f}, \\
k_{s} \frac{\partial T_{s}}{\partial n} & =k_{f} \frac{\partial T_{f}}{\partial n} .
\end{aligned}
$$

They are applied to the body/fluid interface providing the continuity of thermal fields and heat flux between the body and flow at the interface.

As compressible effects and turbulent effects are taken into account, the energy equation is coupled with the momentum equation and the speed of sound is not fixed. Additionally, the coupling between both the compressible fluid problem and the heat transfer problem is given by the Conjugate Heat Transfer (CHT) boundary conditions. A finite volume code is used to discretize both the fluid mechanics and the heat transfer coupled problem.

The fluid problem is solved through the RANS equations for turbulent flow and its solution is coupled with the elliptic heat problem that solves the temperature field in the solid part. The turbulent effects are added using a $k-\omega$ SST model [23]. The computational domain is discretized with 5.91 $10^{6}$ hexahedrons. More details about the grid generation and convergence are detailed in a previous work [24]. In order to solve correctly the velocity boundary layer, we have ensured that $y^{+}<1$. As the fluid is a gas, $\operatorname{Pr} \approx 1$, the velocity and the thermal boundary layers thickness are both equivalent $\delta_{v} \approx \delta_{T}$.

For a CHT analysis, the energy equation is solved throughout the fluid and solid solution domain with an efficient implicit thermal coupling at the fluid/solid interface. In the body/fluid interface continuity of the thermal fields is provided by specifying the equality of temperature and heat fluxes of a body and a flow at the vicinity of interface. The coupled heat transfer within a fluid and an adjoining solid, known as conjugate heat transfer, is computed during the simulation.

\section{Computational tool}

As compressible and turbulent effects are taken into account, the energy equation is coupled with the momentum equation and the speed of sound is not fixed. A finite volume code is used to discretize both the fluid mechanics and the heat transfer coupled problem.

The coupled system of Equations (2)-(4) and (5) are solved using an implicit second-order discretization method to compute the Navier-Stokes equations and to calculate the density, temperature, pressure and velocity fields at the steady state. For these steady simulations, an iterative process is used to ensure the steady state condition to be satisfied with low residuals. To accelerate the solver convergence, a coupled algebraic multigrid method based on $\mathrm{V}$ fixed cycles is used.

For the conjugate heat transfer analysis, the energy equation is solved throughout the fluid and solid domains with an implicit thermal coupling at the fluid/solid interface. The coupling between Equations (2)-(4) and (5) is performed at each iteration on the body/fluid interface, forcing the continuity of the temperature field and energy conservation between the solid and the flow at the interface. In the absence of source terms at this interface, energy conservation implies heat flux continuity. These compatibility conditions are additional equations that must be satisfied in combination with the fluid and thermal subsystems to solve the coupled problem. 


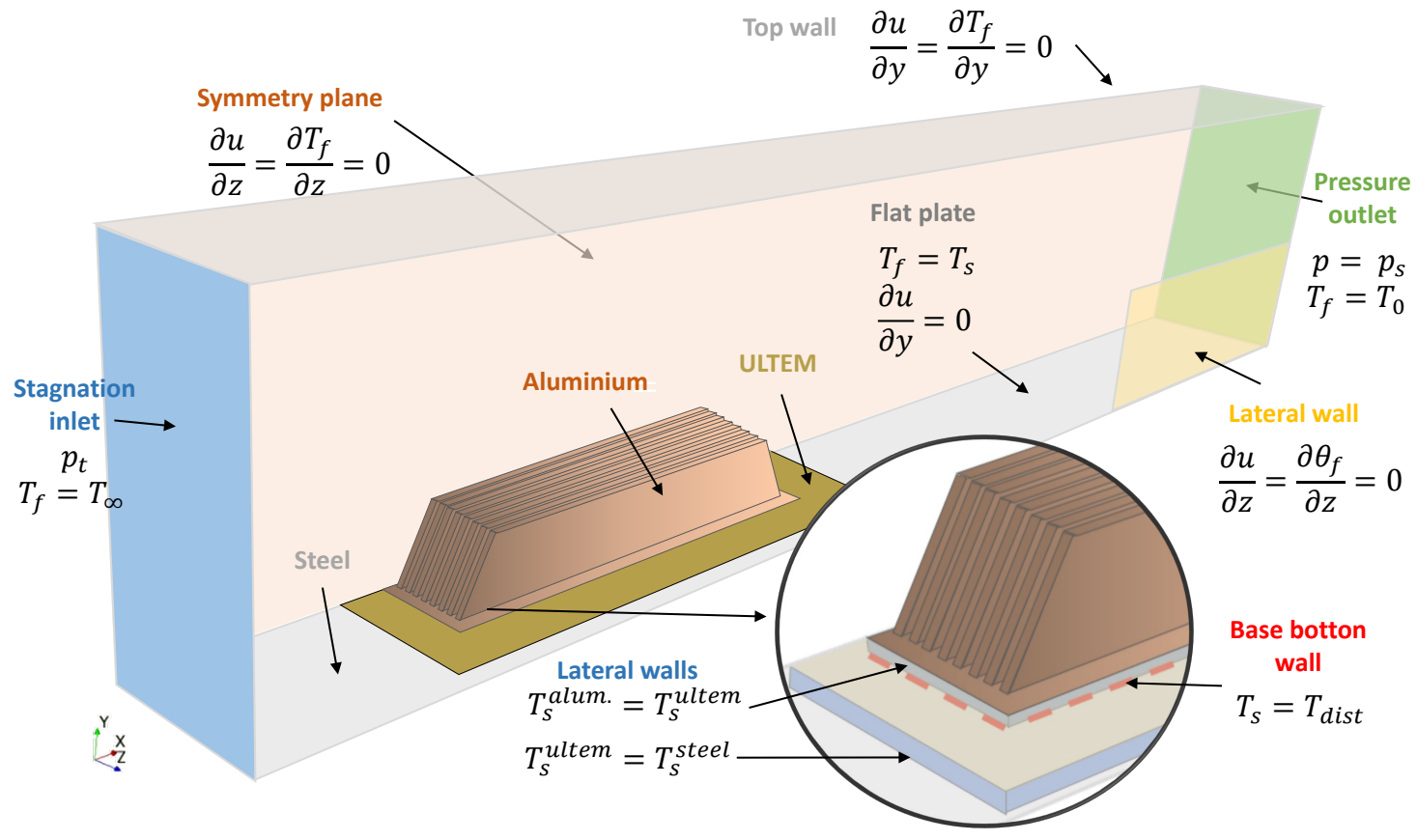

Fig. 6 Boundary conditions imposed at the different surfaces of half fluid and solid domain (symmetric hypothesis).

\section{Results}

An experimental campaign was performed to characterize the SACOC performances, and one of the main scopes of this paper is to compare the experimental results with the ones obtained by numerical computations carried out in parallel. Compressible effects should be taken into account, having the problem a Reynolds number of $R e \sim 10^{6}$ and a Mach number of $M \sim 0.4$. In this work, experimental validation and flow analysis, including aerodynamic and thermal measurements, are offered.

Overall results for pressure drop and heat transfer, collected in Table 2, show a fairly good agreement in both cases. The pressure drop is computed as the total pressure difference between UMS1 and DMS2 in a region laterally limited by the planes $Z / H= \pm 0.3$, so the fins with some margins are included and the uncertainties induced by the impossibility of characterizing the flow very close to the lateral walls do not affect the calculations. In the experiments, a slightly higher pressure drop is observed, probably induced by the irregularities and gaps intrinsic to the tunnel and the CFD obviates. In the heat exchanged, a similar result of little higher values in the experiments can be seen. In this case, the extra heat measured can be explained by the nonperfectly adiabatic insulation of the oil pan, liberating part of the heat as free convection to the test room through its bottom.

\begin{tabular}{c|c|c} 
& $\Delta p[\mathrm{~Pa}]$ & $\dot{Q}[\mathrm{~W}]$ \\
\hline Exp. & 685.9 & 516.5 \\
Num. & $664.4(3.2 \%)$ & 510.3
\end{tabular}

Table 2 Comparison of the pressure drop $\Delta p$ and the total heat transfer $\dot{Q}$

Fig. 7 compares the experimental and numerical total pressure profiles in sections UMS1, DMS1 and DMS2. These results are obtained averaging the nondimensional pressure values between $Z / H= \pm 0.22$, considered to be a region of interest. The total pressure at UMS1 obtained by CFD is the result of using the experimental velocity data as the boundary condition in that section. Nevertheless, both downstream planes numerical results are independent of the measurements. In general, all sections present very similar values and trends, being the numerical results within the standard deviation of the experimental data for most of the occasions. It seems adequate to point out that the dispersion 
in the Kiel measurements increases close to the top wall, which can be related to the openings in the wall to insert the probes.
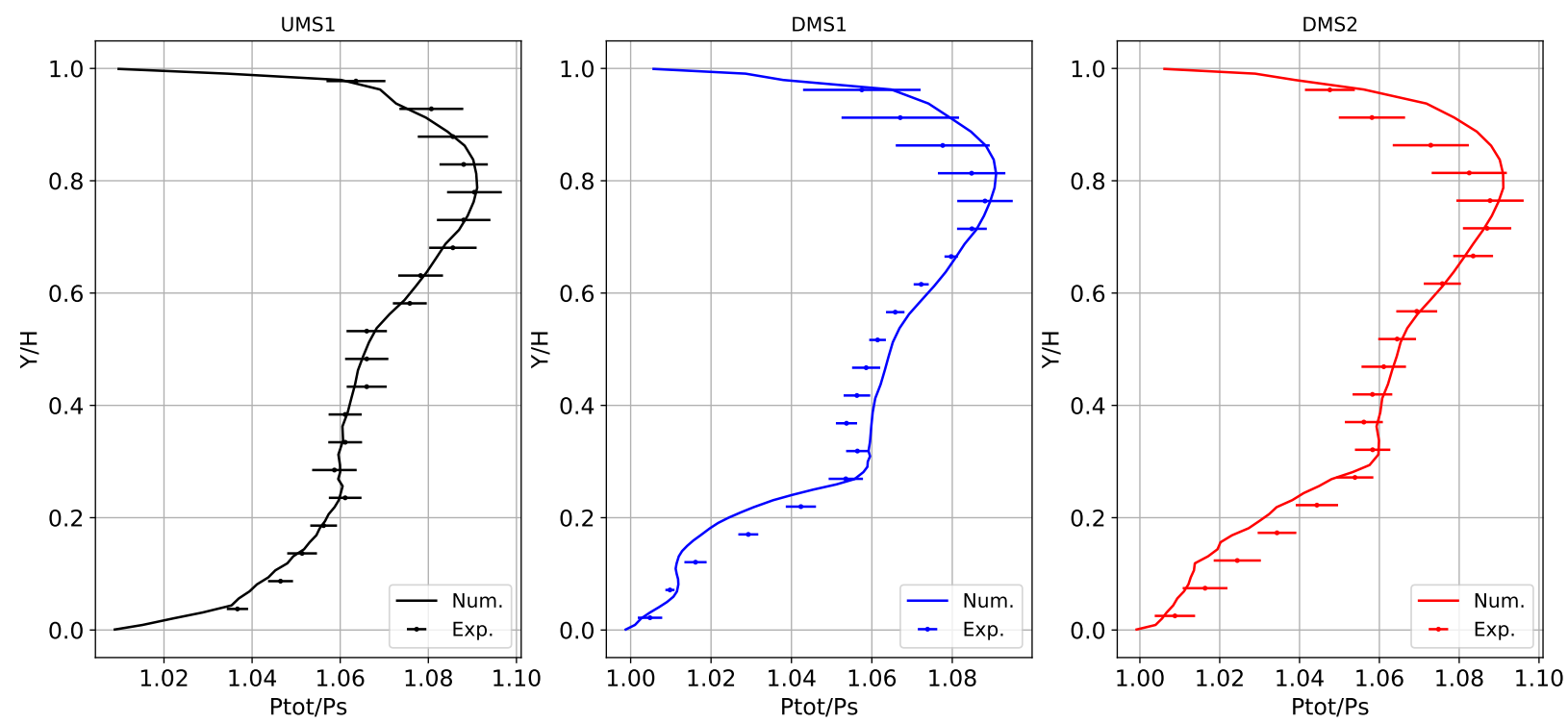

Fig. 7 Non-dimensional total pressure profile comparison between experimental and numerical results at UMS1, DMS1 and DMS2.

Fig. 8 compares the experimental and numerical temperature profiles at four different sections at $Z / H=0$ showing a good matching in the temperature slope and maximum value location. The main differences found can be explained due to a velocity under prediction in the simulations, which influences the values of total temperature. This explains also the reason why the deviation in the experiments decreases as the distance from the fins increases.
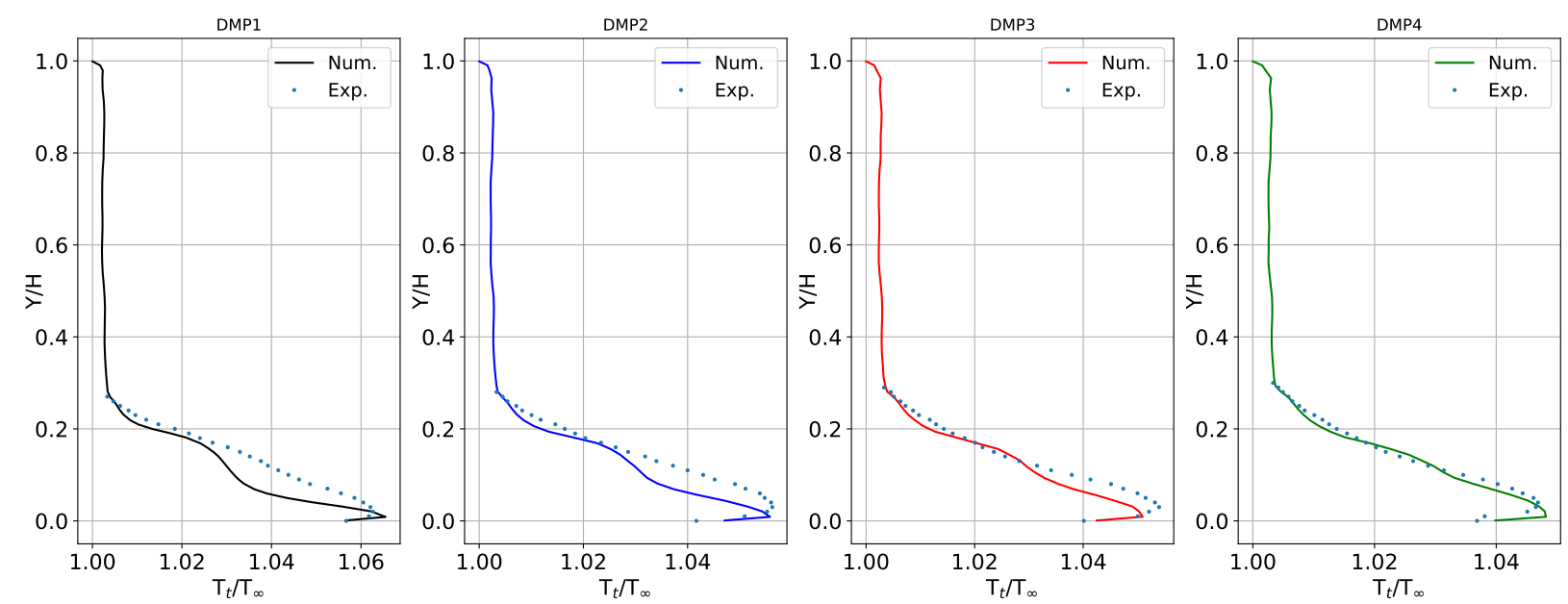

Fig. 8 Non-dimensional total temperature profile comparison between experimental and numerical results at DMP1, DMP2, DMP3 and DMP4.

On the other hand, Fig. 9 depicts the contours of the vorticity field at different cross sections of the SACOC obtained computationally. It can be easily noticed in this representation how the two main vortexes of the problem are captured. A detailed view of the vorticity field between the fins of a particular cross section is also presented. 


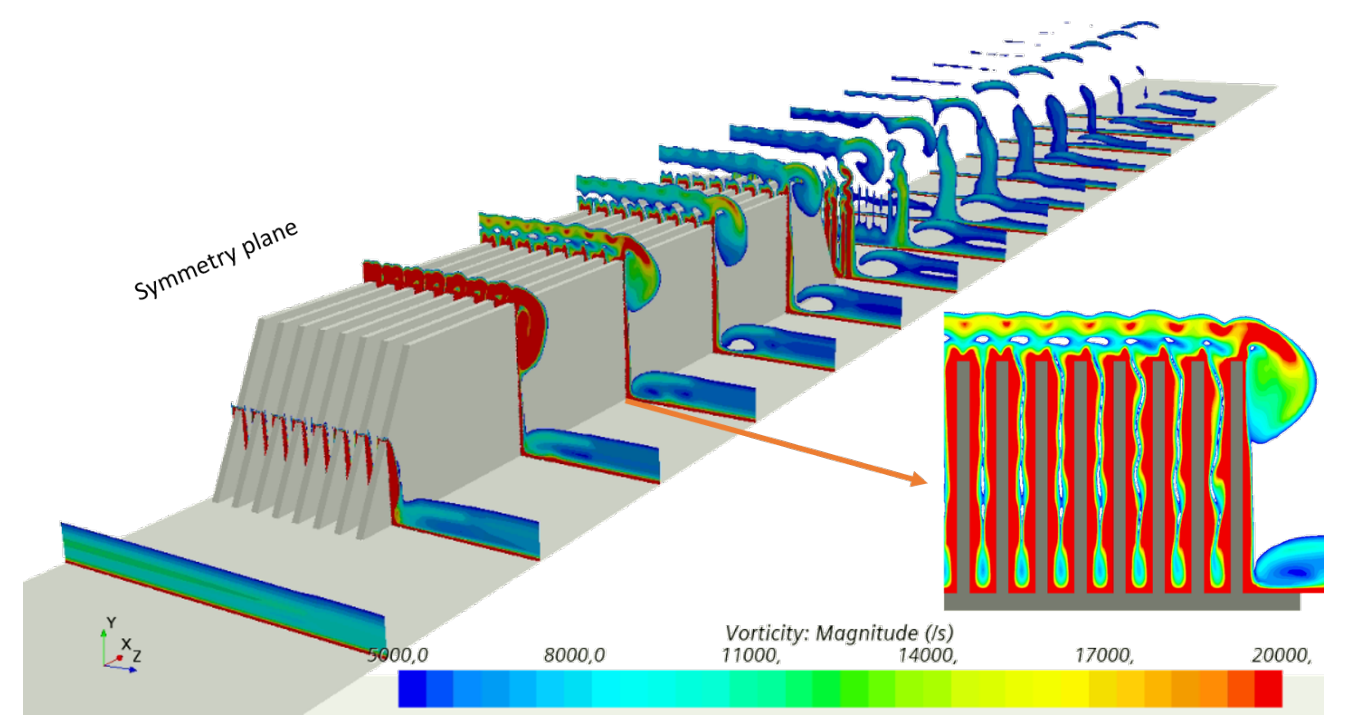

Fig. 9 Vorticity isocontour at different YZ sections.

\section{Conclusion}

This work presents a numerical comparison between the experiments performed in the wind tunnel facility used by UPV and the numerical computations of the equivalent fluid-thermal problem. Measurements with Kiel probes were used to determine the total pressure at different positions of the wind tunnel. For the thermal characterization, a thermocouple array characterizes the thermal boundary layer after the fins along the symmetry plane, whereas a thermographic camera images the heat exchanger from above. A numerical finite volume code computes the turbulent and compressible flow between the heat exchanger taking into account the coupled thermal problem. The experimental pressure and temperature profiles are compared to their equivalent numerical counterparts presenting a good matching.

In summary, a robust aerothermal simulation methodology for this kind of surface heat exchangers has been demonstrated. The resulting numerical data, supported by the experimental campaign, can therefore be used to perform an analysis of the relevant flow structures regarding the aerothermal performance of the SACOC and to design optimized fin shapes that minimize the pressure drop. Special consideration is given to the turbulent thermal wake that may have an appreciable impact on the downstream components of the engine.

\section{Acknowledgments}

This project has received funding from the Clean Sky 2 Joint Undertaking under the European Union's Horizon 2020 research and innovation programme under grant agreement No 831977 Aerodynamic upgrade of Surface AirCooled Oil Coolers (SACOC). Leo M. González acknowledges the financial support from the Spanish Ministry for Science, Innovation and Universities (MCIU) under grant RTI2018-096791-B-C21 Hidrodinámica de elementos de amortiguamiento del movimiento de aerogeneradores flotantes. The authors also wish to thank Safran Aircraft Engines for their kind permission to share the data presented in this publication.

\section{References}

[1] Sousa, J., Villafane, L., and Paniagua, G., "Thermal analysis and modeling of surface heat exchangers operating in the transonic regime," Energy, Vol. 64, 2014, pp. 961-969. https://doi.org/10.1016/j.energy.2013.11.032

[2] Villafañe, L., and Paniagua, G., "Aerodynamic impact of finned heat exchangers on transonic flows," Experimental Thermal and Fluid Science, Vol. 97, 2018, pp. 223-236. https://doi.org/10.1016/j.expthermflusci.2018.04.012

[3] Jonsson, H., and Moshfegh, B., "Enhancement of the cooling performance of circular pin fin heat sinks under flow by-pass conditions," Proceedings of the Eighth IEEE Inter Society Conference on Thermal Phenomena (ITHERM), San Diego,CA, Vol. 24, No. 2, 2002, pp. 425-432. 
[4] Biber, C., and Belady, C., "Pressure drop predictions for heat sinks: what is the best method?" Adv Electron. Packag., Vol. 19, No. 2, 1997, pp. 1829-1835.

[5] Outirba, B., and Hendrick, P., "Development and testing of advanced surface oil coolers for aero-engines," ISABE, 2013.

[6] Ko, J., Kim, S., Ha, M., Min, J., Stieger, R., Mason, S., Doo, J., and Son, C., "A study on the installation of the surface air-oil heat exchanger for the application to aero gas-turbine engine," ISABE, Vol. 19, 2013.

[7] Kim, S., Min, J., Ha, M., and Son, C., "Investigation of high-speed bypass effect on the performance of the surface air-oil heat exchanger for an aero engine," International Journal of Heat and Mass Transfer, Vol. 77, 2014, pp. 321-334.

[8] Adams, J., "Advanced heat transfer surfaces for gas turbine heat exchangers," PhD thesis. University of Oxford, Vol. 19, 2004.

[9] Doo, J., Ha, M., Min, J., Stieger, R., Rolt, A., and Son, C., "An investigation of crosscorrugated heat exchanger primary surfaces for advanced intercooled-cycle aero engines. Part-I: Novel geometry of primary surface," Int. J. Heat Mass Transfer, Vol. 55, 2012, pp. 5256-5267.

[10] Doo, J., Ha, M., Min, J., Stieger, R., Rolt, A., and Son, C., "An investigation of crosscorrugated heat exchanger primary surfaces for advanced intercooled-cycle aero engines (Part-II: Design optimization of primary surface)," Int. J. Heat Mass Transfer, Vol. 61, 2013, pp. 138-148.

[11] Z.G. Qu, Y. H., W.Q. Tao, "Three-dimensional numerical simulation on laminar heat transfer and fluid flow characteristic of strip fin surface with X arrangement of strips," J. Heat Transfer, Vol. 126, 2004, pp. 697-707.

[12] W.Q. Tao, T. L., Y.P. Cheng, "The influence of strip location on the pressure drop and heat transfer performance of a slotted fin," Numer. Heat Transfer, Part A: Appl., Vol. 52, 2007, pp. 463-480.

[13] Torregrosa, A., Broatch, A., García-Tíscar, J., and Roig, F., "Experimental verification of hydrodynamic similarity in hot flows," Experimental Thermal and Fluid Science, 2020, p. 110220. https://doi.org/10.1016/j.expthermflusci.2020.110220

[14] Serrano, J. R., Arnau, F. J., Gracía-Cuevas, L. M., Samala, V., and Smith, L., "Experimental approach for the characterization and performance analysis of twin entry radial-inflow turbines in a gas stand and with different flow admission conditions," Applied Thermal Engineering, Vol. 159, 2019, p. 113737. https://doi.org/10.1016/j.applthermaleng.2019.113737

[15] Serrano, J. R., Arnau, F. J., García-Cuevas, L. M., Soler, P., and Cheung, R., "Experimental validation of a one-dimensional twin-entry radial turbine model under non-linear pulse conditions," International Journal of Engine Research, 2019 , p. 1468087419869157. https://doi.org/10.1177/1468087419869157

[16] Community Research and Development Information Service, "Novel system removes debris from compressor," Research*eu results magazine, Vol. 50, 2016, p. 22.

[17] Paniagua, G., Cuadrado, D., Saavedra, J., Andreoli, V., Meyer, T., Solano, J. P., Herrero, R., Meyer, S., and Lawrence, D., "Design of the Purdue Experimental Turbine Aerothermal Laboratory for Optical and Surface Aerothermal Measurements," Journal of Engineering for Gas Turbines and Power, Vol. 141, No. 1, 2018. https://doi.org/10.1115/1.4040683.

[18] Alcoa Global Cold Finished Products, "Characteristics of Aluminium 7075," , 2021. URL https://www.spacematdb.com/ spacemat/manudatasheets/alcoa_alloy_7075.pdf. accessed: 2021-05-30.

[19] “ULTEM 1010 properties,” https://www.stratasys.com/es/materials/search/ultem1010 2021. Accessed: 2021-05-26.

[20] Gyimah, G. K., Guo, Z.-n., Huang, P., Jiang, S.-z., Barber, G. C., Liu, G.-x., and Liu, J. W., "Improvers of Pressure-Viscosity Coefficients of Two-Phase Liquid-Solid Lubricants," DEStech Transactions on Engineering and Technology Research, 2016. https://doi.org/10.12783/dtetr/amita2016/3562. URL/http://dpi-proceedings.com/index.php/dtetr/article/view/3562

[21] Wrenick, S., Sutor, P., Pangilinan, H., and Schwarz, E. E., "Heat Transfer Properties of Engine Oils," World Tribology Congress III, Volume 1, ASMEDC, 2005, pp. 595-596. https://doi.org/10.1115/WTC2005-64316. URL https://asmedigitalcollection. asme.org/WTC/proceedings/WTC2005/42010/595/307593

[22] "Steel AIS 304 properties," http://www.matweb.com/search/datasheet.aspx?matguid=bd20a4281ae3430d97cfbebf6904ec50. 2021. Accessed: 2021-06-10.

[23] Menter, F., "Zonal two equation $k-\omega$ turbulence models for aerodynamic flows," 23rd fluid dynamics, plasmadynamics, and lasers conference, 1993, p. 2906.

[24] Miguel Chávez-Modena, Leo Miguel González, Eusebio Valero, "Numerical Optimization of the Fin Shape Experiments of a Heat Conjugate Problem surface air/oil heat exchanger (SACOC)," International Journal of Heat and mass tranfer, 2021. 